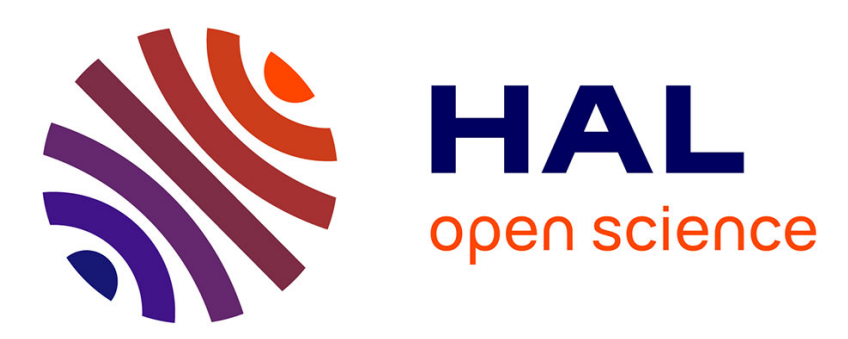

\title{
Towards a methodology for semantic and context-aware mobile learning
}

Fayrouz Soualah-Alila, Christophe Nicolle, Florence Mendes

\section{To cite this version:}

Fayrouz Soualah-Alila, Christophe Nicolle, Florence Mendes. Towards a methodology for semantic and context-aware mobile learning. The Encyclopedia of Information Science and Technology, Third Edition, IGI Global, 10 p., 2013. hal-00876023

\section{HAL Id: hal-00876023 https://hal.science/hal-00876023}

Submitted on 23 Oct 2013

HAL is a multi-disciplinary open access archive for the deposit and dissemination of scientific research documents, whether they are published or not. The documents may come from teaching and research institutions in France or abroad, or from public or private research centers.
L'archive ouverte pluridisciplinaire HAL, est destinée au dépôt et à la diffusion de documents scientifiques de niveau recherche, publiés ou non, émanant des établissements d'enseignement et de recherche français ou étrangers, des laboratoires publics ou privés. 


\title{
Towards a methodology for semantic and context-aware mobile learning
}

\author{
Fayrouz Soualah-Alila*, Christophe Nicolle ${ }^{+}$, Florence Mendes ${ }^{+}$ \\ LE2I, UMR CNRS 6306 \\ University of Bourgogne, Dijon, France \\ *fayrouz.soualah-alila@crossknowledge.com, ${ }^{+}$\{cnicolle, florence.mendes\}@u-bourgogne.fr
}

\section{INTRODUCTION}

Internet and mobile devices open the way towards mobile learning (m-learning), offering new opportunities to extend learning beyond the traditional teacher-led classroom.

M-learning is not only any form of teaching or studying that takes place when the user interacts with a mobile device. It is more than just using a mobile device to access resources and communicate with others. It should take account of the constant mobile situation of the learner.

The challenge here is to exploit this continually changing situation with a system that can dynamically recognize and adapt educational resources and services to the "context" in which the learner operates (localization, surrounding environment, learning time, goals, etc.). However, it is often difficult to identify relevant resources and to organize them into a coherent training course, especially when the learner context is continually changing. M-learning needs a better organization of knowledge, to deliver better in a mobile situation.

A way to address this problem is to create a pedagogical repository of Learning Objects (LOs) and to model learner context. A semantic approach using ontologies provides a semantic organization of learning information and the personalized situation.

This paper presents ongoing research about a context-aware system for Mobile Learning based on ontology. This work is partially funded by CrossKnowledge ${ }^{1}$, the European leader in remote development of leadership and managerial skills using new technologies.

\section{BACKGROUND}

Before any discussion on m-learning, we need to look at the main steps of evolution in the learning domain:

As a first step, learning became distant and moves away from the traditional teacher-led classroom. In the mid-to late 1800's, home study became a legitimate form of education with the development of inexpensive postal services in Europe and across the United States. In 1840, Isaac Pitman used the new postal services to provide a correspondence course, which was in fact the first distance education program. The University of London claimed to be the first university to offer $d$ learning degrees, providing its external program in 1858. Since 1920, educational programs including academics have been broadcasting in Europe. In 1995, Keegan defines distant learning (d-learning) as education and training resulting from the technological separation of teacher and learner, which frees the learner from the necessity of traveling to a fixed place, at a fixed time (Keegan, 1995).

Then with the emergence of computers and the World Wide Web, distance learning evolved and became a critical part of modern education. These new technologies have made $d$-learning distribution easier and faster. In 1999, during a CBT Systems seminar in Los Angeles, a new word was used for the first time in a professional environment "e-learning". Associated with such expressions as online learning or virtual learning, this word was meant to qualify a way to learn based on the use

\footnotetext{
${ }^{1}$ http://www.crossknowledge.com
} 
of new technologies allowing access to online training through the Internet or other electronic media (intranet, extranet, interactive TV, CD-ROM, etc.), so as to develop competencies while the process of learning is independent from time and place. Early e-learning systems, based on computer-based learning, often tried to copy autocratic teaching styles whereby the role of the e-learning system was assumed to be for just transferring knowledge. This is opposed to systems developed later, based on CSCL (Computer Supported Collaborative Learning ), which encouraged the shared development of knowledge and collaborative work. So in 2001, the Commission of the European Communities defined e-learning as "the use of new multimedia technologies and the Internet to improve the quality of learning by facilitating access to resources and services as well as remote exchanges and collaboration".

We cannot separate e-learning from the technology that enables it, which is the Learning Management system (LMS). A LMS is a software application in which training programs are assembled and made available for the learner. Typically, a LMS provides the trainer with a way to create and deliver content, learner participation, and assess learner performance. A LMS may also provide learners the ability to use interactive features such as threaded discussions, video conferencing and forums. Hundreds of LMSs platforms have been developed, the most known are Moodle and Blackboard.

These LMSs support Learning Objects (LOs). There are many descriptions for LOs (Wiley, 2000) (Robson, 2001), but the mostly used definition of a LO was defined by the IEEE-LTSC Learning Object Metadata group as "any entity, digital or non-digital, which can be used, re-used or referenced during technology supported learning" (IEEE 1484.12.1 , 2002). A LO can be a piece of a lesson that has educational content like a simple image, audio or text file, video, simulations, digital pictures, or web pages that include text, image and media, etc. By LOs, educators can use these modular and reusable pieces instead of developing a new lesson from the beginning to the end. In this context metadata (data about data) are tailored towards describing these pieces, making LOs easy to update, search, manage and reuse. There exist a variety of metadata initiatives in the domain like IEEE LTSC's Learning Object Metadata LOM $^{2}$ or ADL's Sharable Content Object Reference Model SCORM ${ }^{3}$. These metadata form pedagogical repositories and can help to catalog LOs to make easy searching and reuse (Wiley, 2000).

Furthermore, every LMS should support tools to help learners, and trainers to manage their learning resources. There are two types of tools: synchronous tools and asynchronous tools. Synchronous tools (chat, shared applications, whiteboard, webcast, video conference, games, simulations...) are interesting pedagogical tools because they promote interactivity. Trainers and learners are simultaneously in front of their respective computers and share live, orally or by script. Asynchronous tools (email, forums, wiki, blog...) are also interesting because they can often structure communities, besides, they do not need trainer presence at the moment of exchange.

A few years later, advances in mobile computing, intelligent user interfaces, context modeling applications and recent developments in wireless communications including Wi-Fi, Bluetooth, multihop wireless LAN and the global wireless technologies such as GPS, GSM, GPRS, 3G and satellite systems have created a wide array of new possibilities for technology users. When these technologies started to be used with e-learning, a new learning paradigm, called mobile learning (mlearning), emerged. This has important didactic dimensions as it frees the learner, who may have spent much of his working day in front of a wired computer. M-learning holds the promise of offering interesting new opportunities for learning as shared, ubiquitous, collaborative, fluid and with an integral access to applications that support learning, anywhere and at anytime (O'Malley, 2003).

Understanding the differences between e-learning and m-learning begins with first defining $\mathrm{m}$ learning. While there are many opinions and ideas surrounding this, the Mobile Learning Consultants

\footnotetext{
${ }^{2}$ http://ltsc.ieee.org/wg12/

${ }^{3}$ http://scorm.com/scorm-explained/
} 
Float Learning defines m-learning as: "the use of mobile technology to aid in the learning, reference or exploration of information useful to an individual at that moment or in a specific use context".

The primary differences between m-learning and e-learning fall into two main categories: time and place and devices:

The first major difference between e-learning and m-learning is the time when learning is expected to take place and the anticipated duration of the learning session. Most e-learning is designed for the learner to sit at a computer at a fixed time and progress through a specified amount of material for a period of time. But m-learning, by its nature, can be done anytime and anywhere. In addition, the small screen sizes of today's mobile devices means by extension, much shorter learning sessions in duration. Learner doesn't want to spend an hour staring at their phone just to complete one LO. Instead, mobile learning is ideal for conveying smaller chunks of information that can be absorbed while waiting for the bus, standing in line, etc.

The second characteristic of m-learning is the use of mobile devices. They vary significantly in their abilities, sizes and prices. The common abilities which merge are their mobility and the possibility to make wireless connections. The main types of mobile devices used in learning process are (Georgiev, 2004):

- NoteBook computers: From one hand they have such abilities as desktop personal computer; from the other hand they have small sizes and support wireless communications.

- Personal Digital Assistant (PDA): They have small sizes and significant processor power. New models support more than 65000 colors, recognize handwritten text and can play different types of multimedia files.

- Cellular phones: The low range devices can be used mainly for voice communication and exchanging text messages (SMS). Some of their disadvantages are low memory capacity and low data transfer rate. The cellular phones from the higher class can be used for Internet access via WAP or GPRS technologies. They also can be used to send and receive multimedia messages.

- Smartphones: They are hybrid devices which combine the abilities of cellular phones and PDA. They are smaller than PDA and bigger than cellular phones. Typically they haven't full sized keyboards and can recognize handwritten text. As they have internet browsers they have potentiality to be successfully used in the mobile multimedia learning.

- Tablets: These are one of the newest mobile devices. They also have a full range of abilities like personal computers. Some of them haven't keyboards but have software to recognize handwritten text.

The transition from the e-learning to the m-learning revolution is characterized also by a large change of terminology. For example, the dominant terms in e-learning are: multimedia, interactive, hyperlinked and media-rich environment. In m-learning terms like spontaneous, situated, connected, informal, private, personal, etc. are used to characterize it. Table 1 contrasts the choice of these terminologies with underlying characteristics of the two types of learning environments.

\begin{tabular}{|c|c|}
\hline E-learning & M-learning \\
\hline Computer & Mobile \\
\hline Multimedia & GPRS, G3, Bluetooth \\
\hline Interactive & Spontaneous \\
\hline Hyperlinked & Connected \\
\hline Collaborative & Networked \\
\hline Media-rich & Lightweight \\
\hline Distance learning & Situated learning \\
\hline More formal & Informal \\
\hline Simulated situation & Realistic situation \\
\hline Hyper learning & Constructivism, situationism, collaborative \\
\hline Lecture in classroom or in internet labs & Learning takes place while mobile \\
\hline More text- and graphics based instructions & More voice, graphics and animation based instructions \\
\hline
\end{tabular}

Table 1. Terminology comparisons between e-learning and m-learning 
To summarize, m-learning as shown in figure 1 proposed by (Georgiev, 2004) is considered as the follow-up of e-learning which, for its part, originates from d-learning.

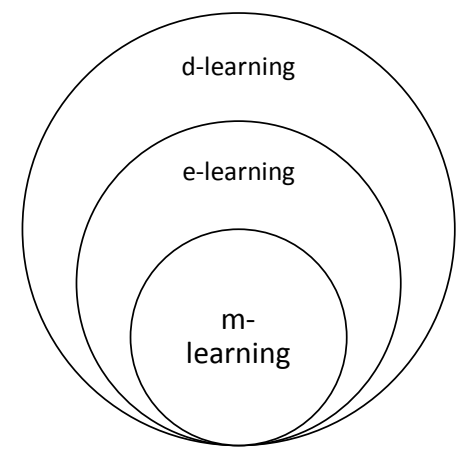

Figure 1. M-learning as part of d-learning and e-learning

From 2005 research and reflection on m-learning increased and no longer focus only on technologies and devices. When considering mobility from the learner's point of view, rather than the technology's, it is more important to say that m-learning is about people moving through environments, learning as they go, using electronic devices that enables connectivity to information sources and communication while they are able to change their physical location. In short, our new definition of mobile learning is "context-aware learning".

In the work that first introduces the term "context-aware", refers to context as location, identities of nearby people and objects, and changes to those objects. In a similar definition, (Brown, 1997) defines context as location, identities of the people around the user, the time of day, season, temperature, etc. (Ryan, 1997) defines context as the user's location, environment, identity and time. These definitions are too specific. When we want to determine whether a type of information not listed in the definition is context or not, it is not clear how we can use the definition. Context is all about the whole situation relevant to an application and its set of users. We cannot enumerate which aspects of all situations are important, as this will change from an application to another. In some cases, the physical environment may be important, while in others it may be completely immaterial. A new definition was given by (Dey, 2000): "context is any information that can be used to characterize the situation of an entity. An entity is a person, place, or object that is considered relevant to the interaction between a user and an application, including the user and application themselves". This definition makes it easier for an application developer to enumerate the context for a given application scenario.

The most manipulated context dimensions in researches are: physical context (spatial, temporal, environment), device context, user context and specific context of the application domain (Dey, 2000). We briefly describe these different dimensions below:

- Spatial dimension: The simplest form refers to the position (coordinates), or place (at home, in a train, in a plane, in a store, etc.). Today, there are many technologies for capturing and tracking these features such as GPS systems, wireless networks or proximity detection methods.

- Time dimension: Time is important in order to find out and manage the history of contexts to enrich the current context. Sequencing and scheduling activities, actions or events in time may also be important for decisions taken by the system. For example, the history and the behavior tracing of users enables access to past contextual information to infer future behavior of the latter, by analyzing past interactions to offer a share of better future resources.

- Environment dimension: In some systems, it is necessary to measure the characteristics of the environment around the user to regulate the system's operations. For example, the system may measure the noise level to adjust the sound of the mobile device.

- Device dimension: This dimension considers the characteristics of mobile devices: PDA, Smartphone, tablet, laptop, etc. Different properties define these devices: screen size, screen resolution, processor power, memory capacity, etc. They aim to provide an interaction interface 
between the system and the user on the move. Therefore, the system has to present the appropriate content depending on the characteristics of these devices.

- User dimension: It is a set of data that characterizes a user or a group of users. In this model, the system collects different types of information. There are two types of information. The first type describes general information about the user such as first name, last name, age, birthdate, nationality, language. The second type varies according to the different application domains: preferences, knowledge, skills, role (learner, teacher, administrator, etc.), centers of interest, etc.

In the case of m-learning, location, time, identity and activity are the primary context types for characterizing the situation of a particular user in a mobile LMS. These context types not only answer the questions of who, what, when, and where, but also act as indices into other sources of contextual information. For example, given a person's identity, we can acquire many pieces of related information such as user tasks, roles, beliefs, desires, objectives, relationships to other users in the environment, etc. Furthermore, context can be information about devices and physical environment (e.g. lighting, noise levels) since this may change the way users interact with any device they may be using (figure 2).

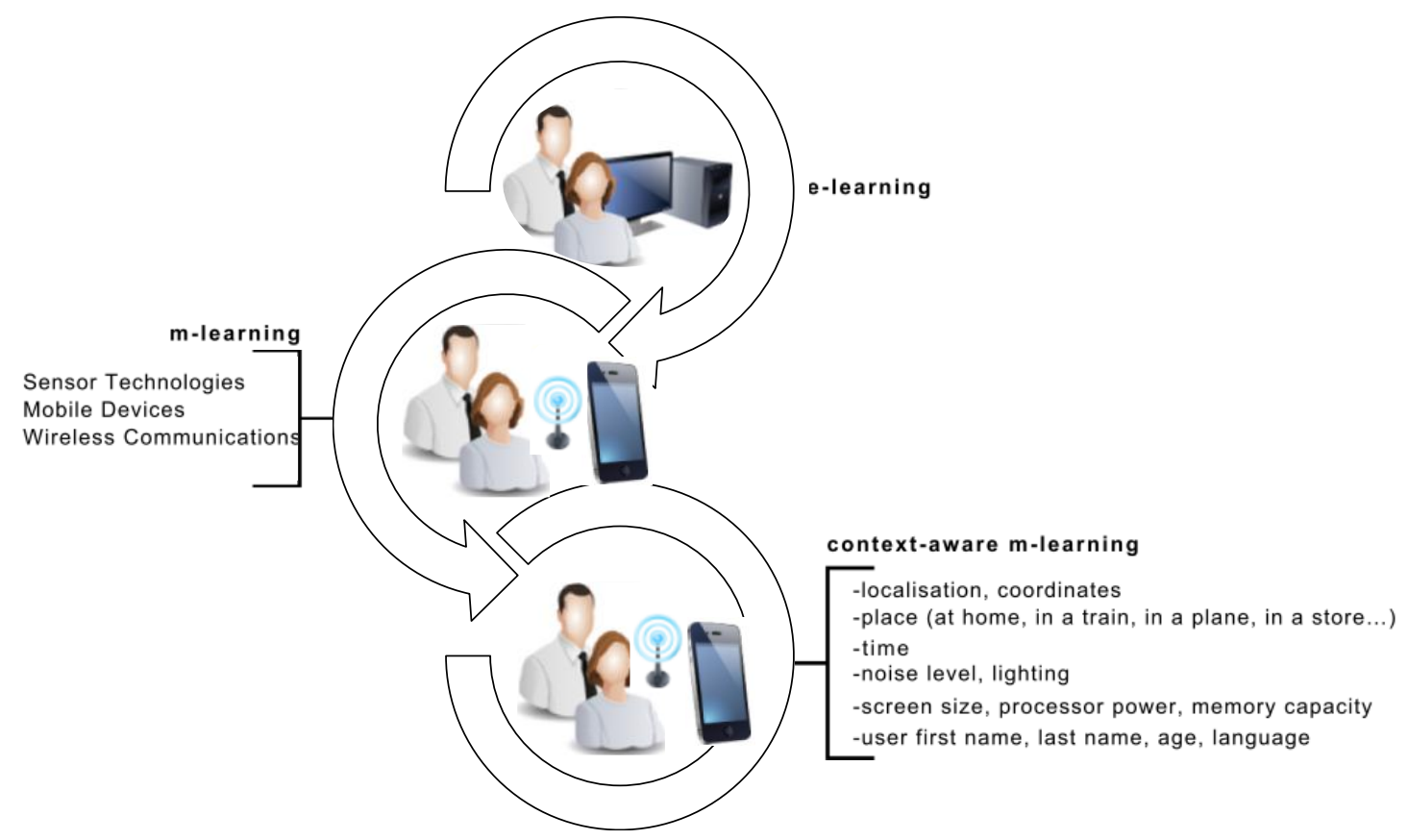

Figure 2. Shifts in e-learning

Context-aware computing in the m-learning domain offers many advantages. (Chen, 2002) lists them:

- Accessibility: Learners have access to their documents, data, or videos from anywhere.

- Interactivity: Learners can interact with experts, trainers, or peers in the form of synchronies or asynchronous communication. Hence, the experts are more reachable and knowledge is more available.

- Immediacy: Wherever learners are they can get any information immediately. Therefore, learners can solve problems quickly. Otherwise, the learner may record the questions and look for the answer later.

- Adaptability: Learners should get the right information at the right place, at the right time in the right way.

- Placing of instructional activities: The learning could be part of our daily life. The problems encountered, as well as the knowledge required, are all presented in the nature and authentic forms. It helps learners to notice the features of problem situations that make particular actions relevant.

Context-aware applications need acceptable context modeling and reasoning techniques. Modeling 
context knowledge is an important task to support the delivery of the right information at each moment, to adapt and to personalize the information, and to anticipate the results. There are many methods for modeling context (Sielis, 2012). (Schilit, 1994) used key-value models. (Strang, 2004) proposed markup schema models like XML. Others like (Henricksen, 2003) used graphical models such as UML (Unified Modeling Language) or ORM (Object Role Extension). Finally an ontology-based context model was proposed by (Bouzeghoub, 2007).

Ontology represents the knowledge on a specific domain using semantic relationships between concepts describing the domain. This set forms a semantic network. Ontologies provide many useful features for intelligent systems (Gruber, 1991): first, ontologies provide the capacity to create a common data model for all applications in an organization. They can set up shared and centralized repositories. Also, ontologies provide information modeling independent from applications which use them. Besides its obvious contributions from classic approaches of comments by keywords, ontologies are used for sharing and reusing data, and for improving communication. Therefore, ontologies are a promising instrument to model information, because of their high and formal expressiveness, and the possibilities for applying ontology reasoning techniques (Chen, 2004).

By using context awareness ontology, context data are collected and managed by certain entities and are expressed by means of references to ontological concepts and relations. The concepts and the relations-associations within the ontology can be represented by OWL language. At the same time, ontology can be used to model concepts of the learning domain by adding semantic description to LOs (figure 3).

To build an approach of quality, in recent years international standards (IEEE and ISO) are developing standardization initiatives in educational technologies. They do not seek to standardize teaching methods or multimedia technologies used. They just aim to set up rules that will help in sharing and reusing educational modules. For example, ADL has recognized the need to have a model that aims to make learning platforms and their content interoperable. This model is the standard SCORM which has become a major asset for distance learning platform. To define a SCORM course, the author builds SCOs (Sharable Content Object). SCOs are the building blocks of a course, then explain how to link them. A SCO is a learning unit that has a pedagogical meaning, which can be reused in another course and can be recognized by other SCORM platforms. A SCO may consist of web pages, animations, drawings, videos, etc. A set of SCOs forms a LO, and one or more LOs form a training course.

We can make parallels between the principles of SCORM and semantic Web, emphasizing that they both aim to enable better management of content, and they both adopt the incorporation of metadata on resources. However, the granularity level of knowledge is different: in semantic Web, the entire content of a document is associated to many metadata. In SCORM, the granularity of knowledge stops at the SCOs (the resource). However, a SCO can itself be composed of one or more Web pages, so the content of a SCO is a kind of box, inaccessible to semantic search mechanisms. In addition, SCORM isolates metadata describing a resource from the resource itself, to help access, search, sharing and reuse; each SCO must be described using metadata and semantic annotations. Indeed, a non-indexed or annotated SCO cannot be recovered and reused.

By exploiting ontologies in our research project, we may support a LO around small pieces of learning knowledge that are semantically annotated. Then, these pieces may easily be arranged in learning courses and delivered on demand to a user according to his profile needs and context. 


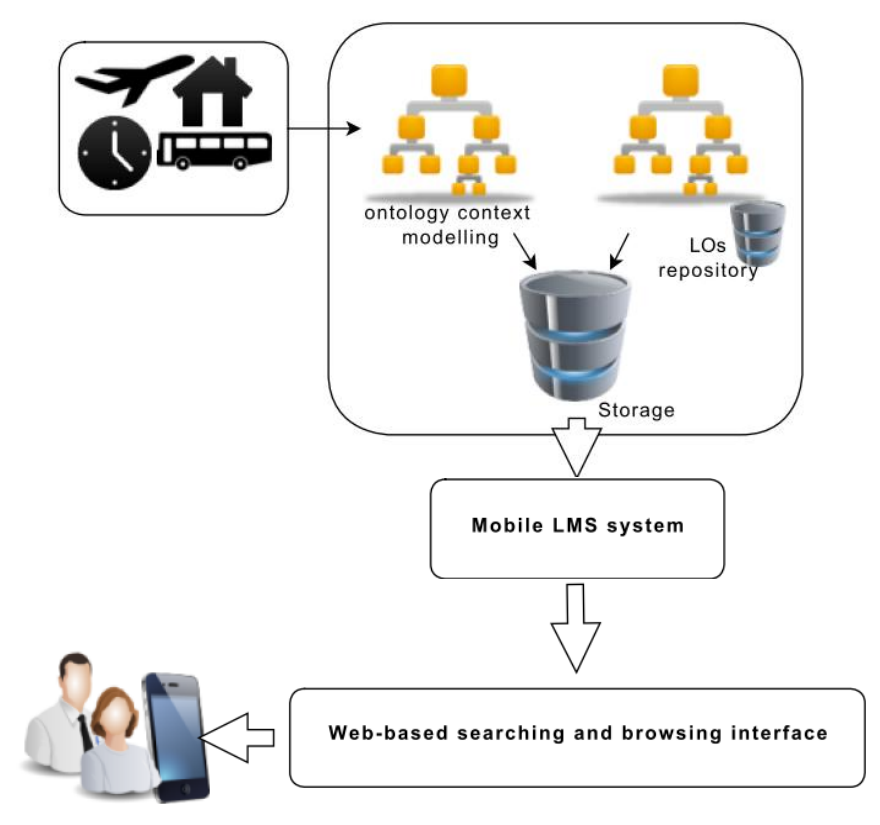

Figure 3. Ontology mapping for mobile learning

\section{FURTHER RESEARCH DIRECTIONS}

In recent years, there have been major advances and research done on opportunities to learn with mobile devices. These new devices provide the possibility of extending the learning environment far beyond the traditional classroom. M-learning aims at replacing predetermined methods of learning with a just-in-time, customized and on-demand process of learning. The key word on m-learning is the context. The context consists of the learner's state, the educational activity's state, the device's state, and the environment's state. Each one of these states is further described by its dimensions. Techniques for modeling the context are multiple. A better representation of context is necessary to fix dynamically which LO to propose to learner.

\section{CONCLUSION}

A way to reach this target is the use of a set of common ontologies that the devices, LMSs and users will use to describe their context. Ontologies are knowledge representation frameworks that enable us to express knowledge in a clear and expressive way with well-defined semantics. Ontologies will help to construct an adaptive, personalized m-learning system and add a semantic interpretation to learning resources. Also, modeling context by ontology will make the $\mathrm{m}$-learning system more adaptive and intelligent.

\section{REFERENCES}

Bouzeghoub, A. \& al., ( 2007). A Situation-Based Delivery of Learning Resources in Pervasive Learning.

Brown, P.J. \& al (1997). Context-Aware Applications: From the Laboratory to the Marketplace. IEEE Personal Communications.

Chen, H. \& al (2004). Semantic Web in the Context Broker Architecture, Pervasive Computing and Communications, Proceedings of the Second IEEE Annual Conference. 
Chen, Y.S. \& al (2002). A Mobile Scaffolding-Aid-Based Bird-Watching Learning System, Proceedings of IEEE International Workshop on Wireless and Mobile Technologies in Education.

Dey, A. (2000). Providing Architectural Support for Building Context-Aware Applications.

Georgiev, T. \& al (2004). M-Learning - a New Stage of E-Learning, International Conference on Computer Systems and Technologies.

Gruber, T.R. (1991). Toward Principles for the Design of Ontologies Used for Knowledge Sharing. International Journal of Human-Computer Studies.

Henricksen, K. \& al (2003). Generating Context Management Infrastructure from High-Level Context Models. Industrial Track Proceedings of the 4th International Conference on Mobile Data Management .

IEEE Standard for Learning Object Metadata. LOM 1484.12.1, 2002

Keegan, D. \& al (1995). Distance Education Technology for the New Millennium: Compressed Video Teaching, ZIFF Papiere. Hagen, Germany: Institute for Research into Distance Education.

O'Malley, C. \& al (2003). MOBILearn WP4-Pedagogical Methodologies and Paradigms: Guidelines for Learning/Teaching/Tutoring in a Mobile Environment.

Quinn, C. (2000). M-Learning: Mobile, Wireless, In-Your-Pocket Learning. LiNE Zine. Fall. In We Need an Educationally Relevant Definition of Mobile Learning.

Robson (2001). Learning Object Tutorial. http://www.eduworks.com/LOTT/tutorial/index.html).

Schilit, B. \& al (1994). Context-Aware Computing Applications. 1st International Workshop on Mobile Computing Systems and Applications.

Schilit, B. \& al (1994). Disseminating Active Map Information to Mobile Hosts. IEEE Network.

Sharples, M. (2006). Big Issues in Mobile Learning: Report of a Workshop by the Kaleidoscope Network of Excellence Mobile Learning Initiative: LSRI, University of Nottingham.

Sielis, A. \& al (2012). Context-Aware Recommendations Using Topic Maps Technology for the Enhancement of the Creativity Process.

Strang, T. \& al (2004). A Context Modeling Survey. First International Workshop on Advanced Context Modeling, Reasoning And Management (UbiComp '04), Nottingham England.

Trifonova, A. \& al (2004). A General Architecture for M-Learning. The fourth IEEE Conference on Advanced Learning Technologies.

Wiley, D.A. (2000). Connecting Learning Objects to Instructional Design Theory: A Definition, a Metaphor, and Taxonomy. The Instructional Use of Learning Objects. 


\section{ADDITIONAL READINGS}

Soualah-Alila, F., C. Nicolle, F. Mendes and C. Cruz C. (2011). Recommender System for Combination of Learning Elements in Mobile Environment. M-learning 2012 International Conference. Berlin, Germany.

Soualah-Alila, F., C. Nicolle, F. Mendes (2012) Semantic and Contextual Approach For the Recommendation of Learning Modules in Mobility. IEEE Learning Technilogy Newsletter 14, Issue 2, 2012.

Soualah-Alila,F., C. Nicolle, F. Mendes (2013). Recommandation de Parcours de Formation dans un Contexte Mobile, 14 ème Conférence ROADEF de la Société Française de Recherche Opérationnelle et Aide à la Décision.

\section{KEY TERMS}

Blackboard: This is an enterprise software company with its corporate headquarters in Washington, and is primarily known as a developer of education software, in particular learning management systems. The company provides education, mobile, communication, and commerce software and related services to clients, including education providers, corporations and government organizations.

Computer Supported Collaborative Learning (CSCL): This is a pedagogical approach where learning takes place via social interaction using a computer or through internet. It is characterized by the sharing and construction of knowledge among participants, using technology as their primary means of communication or as a common resource.

Context-Awareness: This is the ability of a system to be aware of its context.

Learning Object (LO): This is the smallest element of meaningful instruction, independent of other pieces of instruction and correlated with a specific learning objective. The Institute of Electrical and Electronics Engineers (IEEE) defines a learning object as any entity, digital or non-digital, that may be used for learning, education or training.

Learning Object Metadata (LOM): This is a data model, usually encoded in XML, used to describe a learning object and similar digital resources used to support learning. The purpose of learning object metadata is to support the reusability of learning objects, to aid discoverability, and to facilitate their interoperability, usually in the context of online learning management systems.

Moodle: Abbreviation for Modular Object-Oriented Dynamic Learning Environment. It is a free source e-learning software platform, also known as Learning Management System. Moodle helps learners create online courses with a focus on interaction and collaborative construction of content, and is in continual evolution.

Ontology: An explicit formal specification of how to represent the objects, concepts, and entities existing in an area of interest, and the relationships among them.

Semantic Web: The term was coined by Tim Berners-Lee who defines the semantic Web as a web of data that can be processed directly and indirectly by machines. In other words, semantic Web is a mesh of information linked up in such a way so as to be easily processable by machines, on a global scale. 
Sharable Content Object Reference Model (SCORM): This is a collection of standards and specifications for web-based e-learning. It defines communications between client side content and a host system called the run-time environment, which is commonly supported by a learning management system.

Web 2.0: This is a concept where internet is viewed as a medium in which interactive experience, in the form of blogs, wikis and forums, plays a more important role than simply accessing information. 